DOI: https://doi.org/10.24867/06BE32Vulin

\title{
VIŠEKRITERIJUMSKO ODLUČIVANJE U PLANIRANJU AUTOMATIZACIJE ELEKTRODISTRIBUTIVNIH MREŽA
}

\section{MULTIPLE-CRITERIA DECISION MAKING IN POWER DISTRIBUTION NETWORK AUTOMATION PLANNING}

\author{
Miloš Vulin, Fakultet tehničkih nauka, Novi Sad
}

\begin{abstract}
Oblast - ELEKTROTEHNIKA I RAČUNARSTVO
Kratak sadržaj - U radu je prikazan pristup za određivanje optimalnog plana automatizacije (optimalnog broja $i$ lokacije uređaja za automatizaciju) u elektrodistributivnim mrežama u kojima se pouzdanost meri korišćenjem indeksa SAIDI i SAIFI. Prikazani pristup određuje najbolji plan automatizacije korišćenjem alata za višekriterijumsku optimizaciju. U prvom koraku se određuje skup nedominantnih rešenja (planova automatizacije), a zatim se korišćenjem alata za višekriterujmsko odlučivanje bira najbolji plan iz dobijenog skupa.
\end{abstract}

Ključne reči: Pouzdanost elektrodristributivnih mreža, automatizacija, visekriterijumsko odlučivanje

\begin{abstract}
This paper presents the approach for optimal network automation planning (obtaining the optimal number and location of automation devices) in the networks where reliability is measured by using indices SAIDI and SAIFI. Presented approach defines the best automation plan by employing the tools for multiple criteria optimization. First, the set of non-dominated solutions (automation plans) is determined and then the best plan in the set is obtained by using the tool for multiple criteria decision making.
\end{abstract}

Keywords: Reliability of power distribution networks, automation, multiple criteria decision making

\section{UVOD}

Jedna od glavnih karatkteristika distribitivog sistema jeste zadovoljenje što većeg nivoa pouzdanosti. Pouzdanost napajanja se danas postiže primenom različitih vidova distributivne automatike i softverskih alata. Pouzdanost distributivnog sistema zavisi od pouzdanosti njegovih elemenata. Elementi distributivnog sistema (rasklopna oprema, transformatori, sabirnice, vodovi...) mogu se u analizama modelovati na različite načine, a najčešće se opisuju sa dva stanja [1]:

- $\quad$ stanje ispravnog rada $\mathrm{i}$

- $\quad$ stanje otkaza.

Pouzdanost mere svi operatori distributivnog sistema $u$ celom svetu. Jedan od načina merenja je preko neekonomsih i ekonomsih pokazatelja pouzdanosti. Danas jedna od najčeće primenjivanih tehnika za unapređenje pouzdanosti je automatizacija distriibutivne mreže, koja

\section{NAPOMENA:}

Ovaj rad proistekao je iz master rada čiji mentor je bio dr Željko Popović, doc. se i razamtara u ovom radu. Za određivanje optimalnog nivoa automatizacije $u$ ovome radu je korišćena jedan od energetskih funkcija razvijena u ADMS (Advanced Distribution Management System) softveru (verzija 3.8.2). Kako problem postaje problem višekritrijumske optimizacije pored navedene funkiconalnosti za razmatranje neekonomskih pokazatelja pouzdanosti (SAIDI, SAIFI, ENS) se koristi i metoda višekrtiterijumskog odlučivanja. Kriterijumeske funkcije ovih pokazatelja se sastoje od više različitih kriterijuma, tj. kriterijumi nemaju iste jedinice. Za izbor najboljeg scenarija automatizacije korišćena je metoda višekriterijumskog odlučivanja TOPSIS.

\section{POKAZATELJI POUZDANOSTI U DISTRIBUTIVNIM MREŽAMA}

Pokazatelji pouzdanosti koji će biti obrađeni u ovom radu su SAIFI i SAIDI. Indeks prosečne učestanosti prekida isporuke električne energije - SAIFI (System Average Interruption Frequency Index), predstavlja srednji broj trajnih prekida napajanja potrošača $u$ definisanom vremenskom periodu i definisan je sledećom relacijom [2]:

SAIFI $=\frac{\text { ukupan broj prekida napajanja potrošača }}{\text { ukupan broj usluženih potrošača }}=\frac{\sum \lambda_{i} N_{i}}{N_{T}}$,

gde su:

$\lambda_{i}$ - intezitet otkaza i-tog potrošačkog čvora,

$N_{i}$ - broj korisnika pogođenih prekidom isporuke električne energije usled dugotrajnjog prekida $i$,

$N_{T}$ - ukupan broj korisnika.

Indeks prosečnog trajanja prekida isporuke električne energije $u$ definisanom vremenskom periodu, izražava se u minutima ili časovima i definisan je sledećom relacijom [2]:

SAIDI $=\frac{\text { suma trajan ja prekida po jedinih potrošača }}{\text { ukupan broj usluženih potrošača }}=\frac{\sum r_{i} \lambda_{i} N_{i}}{N_{T}}$

gde su:

$r_{i}$ - vreme potrebno za restauraciju napajanja usled prekida i,

$\lambda_{i}$ - intezitet otkaza i-tog potrošačkog čvora,

$N_{i}$ - broj korisnika pogođenih prekidom isporuke električne energije usled dugotrajnjog prekida i,

$N_{T}$ - ukupan broj korisnika.

Većom zastupljenošću uređaja za automatizaciju (sekcionalizera, indikatora prolaska struje kvara) obezbeđuje se smanjenje broja korisnika pogođenih kvarom i vremena trajanja kvara. Time se unapređuju i gore prikazani pokazatelji pouzdanosti. Određivanje optimalnog nivoa automatizacija je složen, nelinearan, optimizacioni problem sa 
ograničenjima. Da bi se postiglo opšte poboljšanje nije dovoljno razmatrati samo jednu funkciju cilja, dakle postavlja se i rešava višekriterijumska optimizaciona funkcija (problem) [3].

Najvažnije pitanje je kako postići visoki stepen pouzdanosti distributivnog sistema uz minimalne kapitalne troškove (investicije) odnosno naći kompromis između pouzdanosti i potrebnih ulaganja zarad postizanja iste. To obuhvata utvrđivanje optimalnog broja i lokacija postavljanja kontrolnih $\mathrm{i}$ zaštitnih uređaja $\mathrm{u}$ distributivnom sistemu kao i efikasno i sigurno planiranje razvoja distributivne mreže [3].

\section{FORMULACIJA PROBLEMA}

Cilj ovog rada je da odredi optimalan broj i lokaciju sekcionera $\mathrm{i}$ indikatora prolaska struje kvara koje bi trebalo ugraditi u mrežu u cilju postizanja najboljih neekonomskih pokazatelja pouzdanosti. U ovom slučaju, pošto se razmatarju neekonomski pokazatelji pouzdanosti (SAIDI i SAIFI), optimizacioni problem postaje problem višekriterijumske optimizacije. Za rešavanje ovakvog problema je u poglavlju 3.1 prikaza pristup za dobijanje skupa nedominantnih rešenja tj. skupa nedominantnih planova autoamtizacije. Izbor najboljeg plana automatizacije iz dobijenog skupa je urađen korišćenejm metode višekriterijumskog odlučivanja TOPSIS, koja je prikazana u poglavlju 3.2.

\subsection{Matematički model}

Pristup koji je obrađen $u$ ovom radu definiše optimalnu strategiju za automatizaciju elektrodistributivnih mreža ukoliko se pouzdanost određuje na sledeći načina:

- U situaciji kada se uspešnost distributivne kompanije meri samo na osnovu pokazatelja pouzdanosti SAIFI i SAIDI cilj planiranja automatizacije distributivne mreže se može formulisati na sledeći način:

$F 1=\min \{S A I F I, S A I D I$, Trošak automatizacije $\}$

Kriterijumska funkcija (4) predstavljaju višekriterijumsku formulaciju problema planiranja automatizacije distributivne mreže. U (4) su razmatrani pojedinačni kriterijumi koji su izraženi (mereni) u različitim jedinicima i zbog toga se za rešavanje ovoga problema koristi ekvivalentni indeks pouzdanosti [4] i pristup za rešavanje višekriterimskog problema optimizacije zasnovan na metodi ograničenja u prostoru kriterijumske funkcije [5]. Ekvivalenti pokazatelj pouzdanosti, SAFDI, je definisan na sledeći način:

$$
\begin{aligned}
S A F D I= & t_{S A I F I} \cdot \frac{S A I F I}{S A I F I_{C}-S A I F I_{\max B}}+ \\
& +t_{S A F D I} \cdot \frac{S A I D I}{S A I D I_{C}-S A I D I_{\max }}
\end{aligned}
$$

gde je:

$\mathrm{t}_{\text {SAIFI }}, \mathrm{t}_{\text {SAIDI }}$ - težinski faktori kojima se uvažava značaj (težina) pojedničnog indeksa,

$\mathrm{SAIFI}_{c}, \mathrm{SAIDI}_{\mathrm{c}}$ - vrednosti indeksa u mreži sa tekučinim nivoom autoamtizacije,

$\mathrm{SAIFI}_{\operatorname{maxB}}, \mathrm{SAIDI}_{\operatorname{maxB}}$ - vrednosti indeksa pouzdanosti koji bi se imali kada bi se maksimalno dozvoljeni budžet potrošio na njihovo unapređenje. Ove vrednosti se dobijaju rešavanjem (4) za pojedinačni indeks i maksimalni budžet. Kao alternativo rešenje se može uzeti da su ove vrednosti jednake nuli (0).

$\mathrm{Na}$ osnovu prethodnog i korišćenjem metode ograničenja u prostoru kriterijumske funkcije [5] se višekriterijumski problem (4) prevodi u sledeći niz jednokriterijumskih optimizacionih problema:

$$
F 1=\min S A F D I
$$

Uz ograničenja:

$$
\text { Trošak automatizacije } \leq \text { BUDŽET }_{\mathrm{T}}
$$

Variranjem budžetskih ograničenja (7) u (6), odnosno variranjem broja uređaja za automatizaciju koji su na raspolaganju za ugradnju, može se dobiti skup nedominantnih rešenja problema (4). Na ovaj način se dobija skup različitih planova automatizacije koji unapređuju SAIDI i SAIFI, a određivanje najboljeg među njima se vrši primenom metode za višekriterijumsko odlučivanje TOPSIS, prikazane u poglavlju 3.2. Detaljnu formulaciju problema $\mathrm{u}$ terminima mešovitog celobrojnog linernog programiranja (MILP) nije moguće dati u radu zbog ograničenog prostora. Detaljna formulacija je prikazana $u$ master radu [7].

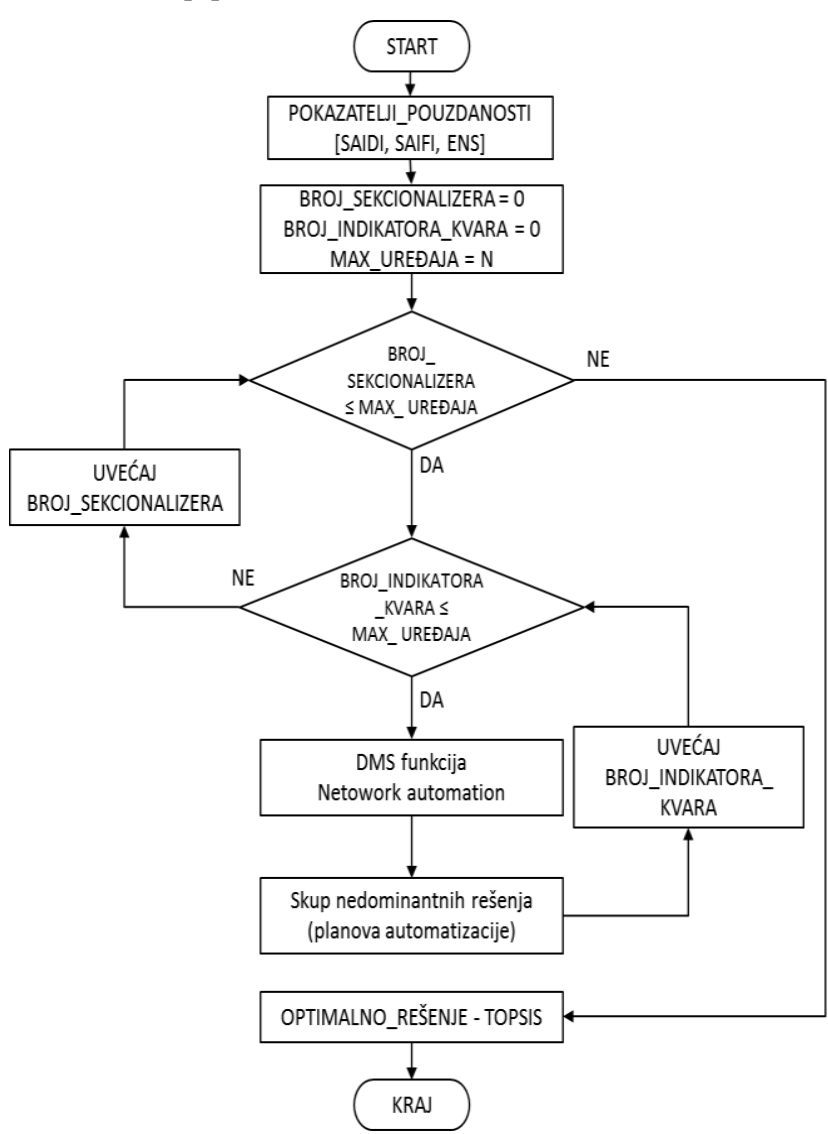

Slika 1. Blok-dijagram višekriterijmskog odlučivanja

Generisanje skupa nedominantnih rešenja korišćenjem napred navednog pristupa je detaljnije prikazano blok dijagramom na slici 1 .

Nakon što je generisan skup nedominantnih rešenja potrebno je metodom višekriterijumskog odlučivanja pronaći najbolje rešenje. U nastavku će biti objašnjeno ukratko kako korišćenjem metode TOPSIS dolazimo do najbolje rešenja 


\subsection{Metoda TOPSIS}

Metoda TOPSIS (Technique for Order Preference by Similiarity to Ideal Solution) je zasnovana na konceptu da izabrana alternativa treba da ima najkraću Euklidovu udaljenost od "idealnog" rešenja i najdalju Euklidovu udaljenost od "anti-idealnog" rešenja, pa se na taj način uvode dve referentne tačke: "idealno rešenje" i "antiidealno rešenje" [5]. Osnovni koraci algoritma za pronalaženje najbolje rešenja korišćenjem metode TOPSIS su sledeći:

1. Transformacija raznorodnih kriterijumskih funkcija

2. Određivanje normalizovanih vrednosti kriterijumskih funkcija

3. Određivanje "idealnog" i "anti-idealnog rešenja"

4. Određivanje mera odstupanja od "idealnog rešenja" i "anti-idealnog rešenja"

5. Određivanje relativne blizine "idealnom rešenju" $C_{j}^{*}$

6 . Formiranje rang-liste alternativa.

$\mathrm{Na}$ kraju prikazani algoritam uvek pruža jedinstveno kompromisno rešenje tako što se formiranjem rang-liste svih alternativa na osnovu vrednosti mere $C_{j}^{*}$ bira najbolja alternativa sa najvećom vrednošću $C_{j}^{*}$. Mera $C_{j}^{*}$ proračunava relativnu blizinu ,idealnom rešenju” svake alternative. Jasno je da za $C_{j}^{*}=1$ dobijeno ,idealno rešenje“, a za $C_{j}^{*}=0$ dobijeno ,,anti-idealno rešenje”, pa je jasno da je najbolja alternativa bliža "idealnom rešenju što je $C_{j}^{*}$ bliže 1. ."

\section{PRIMER PRIMENE}

$\mathrm{U}$ nastavku je opisana test srednjenaponska (SN) distributivna mreža i dati su rezultati proračuna, odnosno određivanja optimalnog nivoa automatizacije sa stanovišta neekonomskih pokazatelja pouzdanosti SAIDI i SAIFI. Poračuni su rađeni na način opisan u poglavlju 3.1 a od opreme za automatizaciju se koriste sekcionalizeri i indikatori prolaska struje kvara

\subsection{Opis test distributivne mreže}

Test distributivna SN mreža koja je korišćena za potrebe proračuna je prikazana na slici 2 .

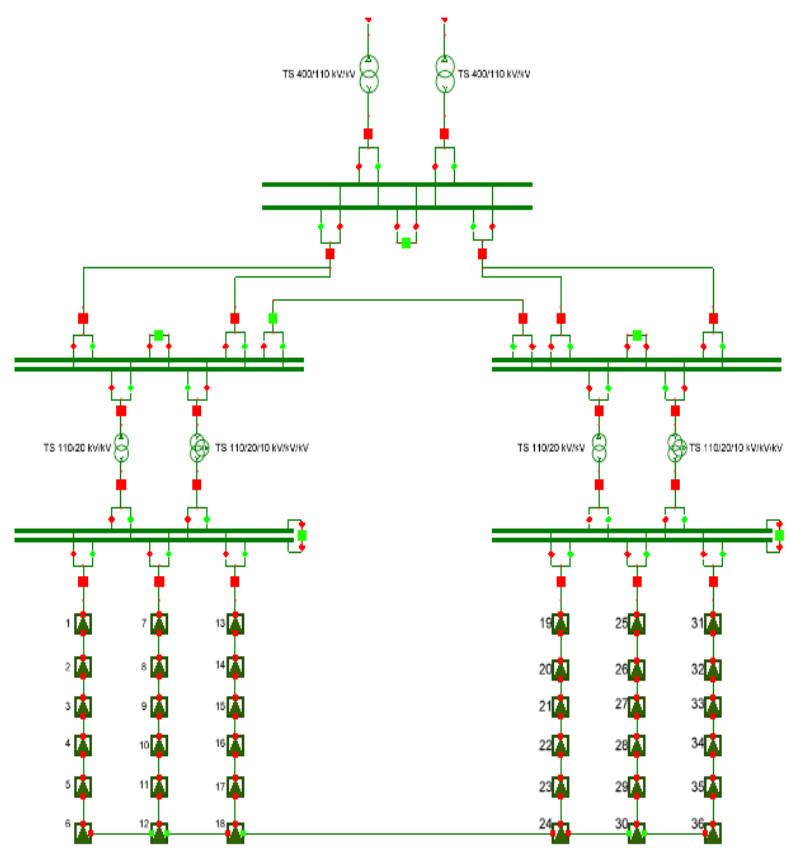

Slika 2. Test mreža
Ona je potencijalno upetljana, sastoji se od dve transformatorske stanice VN/SN, SN dela mreže i potrošačkih čvorova. SN deo mreže se sastoji od šest izvoda i na svakom od izvoda se nalazi po šest potrošačkih čvorova. Potrošački čvorovi na svakom izvodu predstavljaju transformatorske stanice SN/NN sa različitim brojem i tipovima potrošača. Inteziteti kvarova svih sekcija kao i dužine svih sekcija su različite za datu test mrežu i njihove verednosti su date u [7].

\subsection{Određivanje optimalnog plana automatizacije za test mrežu}

Primenom pristupa prikazanog u poglavlju 3.1 su dobijeni različiti planovi automatizacije razmatrane mreže. Oni se međusobno razlikuju kako po broju tako i po mestu ugradnje sekcionalizera i indikatora prolaske struje kvara. Za savki od dobijenih planova se znaju investicioni troškovi i vrednosti pokazatelja pouzdanosti SAIFI i SAIDI. Oni su prikazani na slici 3. Na slici se može videti da indeksi pouzdanosti SAIDI i SAIFI opadaju sa porastom broja ugrađenih uređaja za automatizaciju, odnosno sa porastom investicija.

Da bi se među dobijenim planovima izabrao najbolji(optimalan) plan automatizacije koristi se metoda

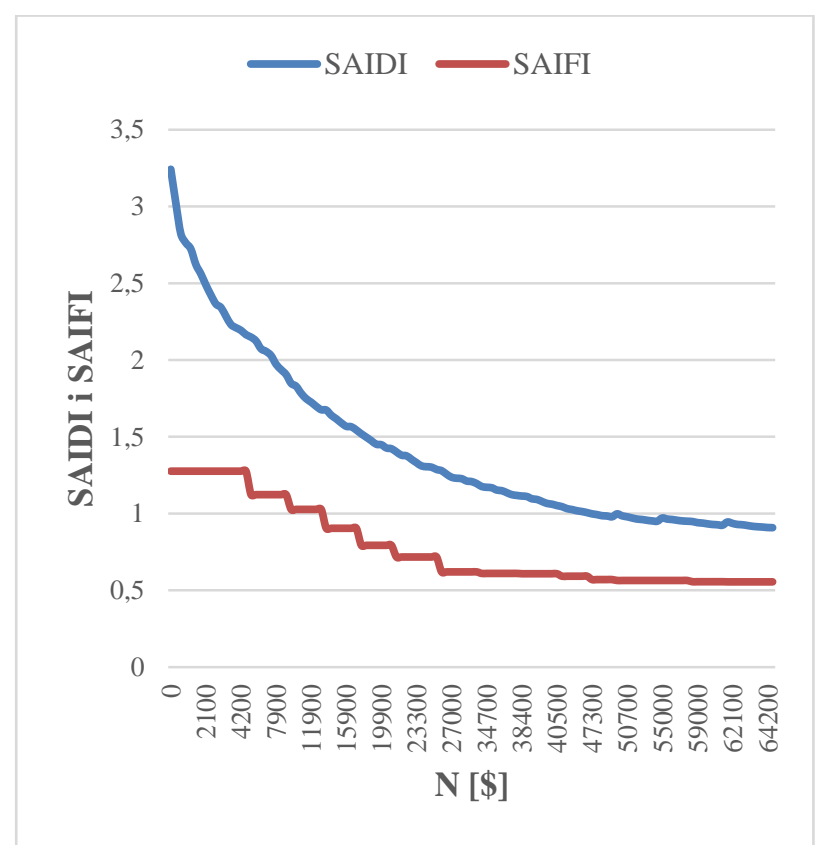

Slika 3. Promena indeksa SAIDI i SAIFI sa povećanjem broja sekcionalizera i indikatora kvara

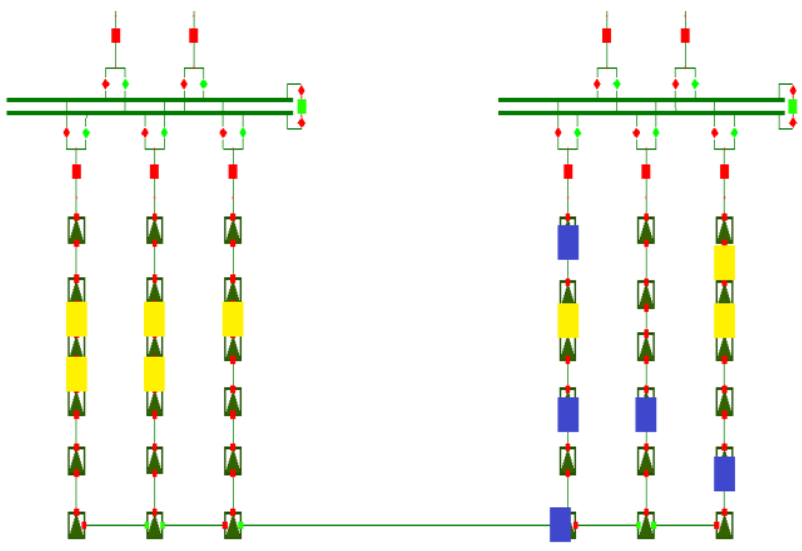

Slika 4. Optimalan broj i lokacija ugrađenih sekcionalizera $i$ indikatora prolaska struje kvara 
višekriterijumsko odlučivanja TOPSIS. Ovde treba imati na umu da je svaki od planova potrebno vrednovati na osnovu raznorodnih kriterijuma. Ti kriterijumi su:

1. Ukupni trošak ugradnje uređaja [\$]

2. Indeks prosečnog trajanje otkaza sistema SAIDI [h/god]

3. Indeks prosečne učestanosti otkaza sistema SAIFI [1/god]

Smatra se da svaki od navedenih kriterijuma ima isti značaj, odnosno istu težinu.

Korišćenjem metode TOPSIS urađeno je rangiranje dobijenih planova automatizacije. Rezulatati rangiranja za najboljih šest planova su prikazani u Tabeli 1 . U ovoj tabeli, na primer, plan 5/7 označava da je to plan u kome je ugrađeno 5 sekcionalizera i 7 indikatora prolaska struje kvara. Iz tabele se vidi da je najbolji plan onaj sa 5 ugrađenih sekcionalizera i 8 indikatora prolaska struje kvara. Ovaj plan, odnosno broj i lokaciju indikatora prolaska struje kvara i sekcionalizera predloženih ovim planom su prikazani na slici 4. Žutom bojom su označeni indikatori prolaska struje kvara, dok su plavom bojom označeni sekcionalizeri

Vrednost koju su imali indeksi SAIDI i SAIFI bez uređaja za automatizaciju je 3.242 i 1.276 , respektivno, a sa opremom za automatizaciju koju definiše najbolji plan automatizacije ovi indeksi su 1.38 i 0.717 , respektivno, uz investiciju od $22400 \$$.

Tabela 1. Rang lista planova automatizacije

\begin{tabular}{|c|c|c|}
\hline Plan & $C_{j}^{*}$ & $\begin{array}{c}\text { Pozicija na } \\
\text { rang-listi }\end{array}$ \\
\hline $5 / 7$ & 0.727648 & 2 \\
\hline $\mathbf{5 / 8}$ & 0.727897 & $\mathbf{1}$ \\
\hline $5 / 9$ & 0.725859 & 5 \\
\hline $5 / 10$ & 0.726246 & 4 \\
\hline $5 / 11$ & 0.712409 & 6 \\
\hline $5 / 12$ & 0.726361 & 3 \\
\hline
\end{tabular}

\section{ZAKLJUČAK}

U radu je prikazan pristup u za određivanje optimalnog plana automatizacije $\mathrm{u}$ elektrodistributivnim mrežama u kojima se koriste pokazatelji SAIFI i SAIDI za merenje pouzdanosti. U ovakvim slučajevima problem planiranja automatizacije postaje višekriterjumski problem.

Za rešavanje ovakvog problema je korišćen algoritam zasnovan na mešovitom celobrojnom linearnom programiranju [7] i pristup za rešavanje višekriterijumskog problema optimizacije zasnovan na metodi ograničenja u prostoru kriterijumske funkcije. $\mathrm{Na}$ taj način se dobija skup nedominatnih planova automatizacije. Izbor najbolje plana automatizacije iz tako dobijenog skupa je urađen korišćenjem metode za višekriterjumsko odlučivanje TOPSIS.
Pristup predložen u ovom radu može da bude koristan alat donosicima odluke za određivanje najboljeg plana automatizacije u elektrodistributivnim kompanijam u kojima se koriste pokazatelji SAIDI i SAIFI za merenje pouzdanosti.

\section{LITERATURA}

[1] M.D. Nimrihter: Elektrodistributivni sistemi, Fakultet tehničkih nauka, Novi Sad, 2009.

[2] IEEE Guide for Electric Power Distribution Reliability Indices 2012.

[3] M.S. Stojanovic, D.S. Tasic, A.T. Ristic: Optimal Allocation of Distribution Automation Devices in Medium Voltage Network, Faculty of Electronic Engineering, University of Nis.

[4] L. Wang, Ch. Singh: Reliability-constrained optimum placement of reclosers and distributed generators in distribution networks using an ant colony system algorithm, IEEE Transaction on Systemes, Man, and, Cybernetics - Part C, Vol. 38., No. 6, 2008, pp. 757764.

[5] S.Opricović: Višekriterijumska optimizacija sistema u građevinarstvu, Građevinski fakultat Univerziteta $\mathrm{u}$ Beogradu, Beograd, 1998.

[6] Ching-Lai Hwang, Kwangsun Yoon: Multiple Attribute Decision Making-Methods and Applications; Springer-Verlag, Berlin, 1981.

[7] M.Vulin: Višekriterijumsko odlučivanje u planiranju automatizacije elektrodistributivnih mreža, master rad, Novi Sad, 2019.

\section{Kratka biografija:}

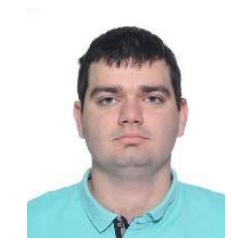

Miloš Vulin rođen je u Bajinoj Bašti 1992. god. Master rad na Fakultetu tehničkih nauka iz oblasti Elektrotehnike i računarstva - Elektroenergetski sistemi odbranio je 2019.god. 